\title{
Assessing Access and Healthcare Quality of Maternal and Child Health Services in Facilities of Kasai Province in the Democratic Republic of the Congo (DRC)
}

Britou Ndela

SANRU

Philippe Ngwala

SANRU

Adrien N'siala

SANRU

Albert Kalonji

SANRU

Felix Minuku

SANRU

Nancy Ntatukidi

SANRU

Harmonie Bokole

SANRU

Jean-Jacques Masumbuku

SANRU

Ngoma Miezi Kintaudi

SANRU

Bien-Aimé M. Mandja ( $\nabla$ mmandja@gmail.com )

Medical School of Kinshasa University https://orcid.org/0000-0003-3846-5746

\section{Research}

Keywords: Democratic Republic of the Congo, Kasai Province, maternal and child health services, access, availability, quality, emergency obstetric care

Posted Date: January 19th, 2021

DOl: https://doi.org/10.21203/rs.3.rs-148519/v1 
License: (c) (i) This work is licensed under a Creative Commons Attribution 4.0 International License. Read Full License 


\section{Abstract}

Background: The Democratic Republic of the Congo (DRC) is classified among the 5 countries with the highest global maternal mortality ratio (MMR) and highest under-five mortality rate (U5MR) in the world. Kasai is one of 14 provinces of the DRC, which have a high U5MR and MMR. Despite this overriding concern, almost no studies have been conducted to assess maternal et child situation in this province. The aim of this study was to assess access, availability, and quality of maternal and child health services in Kasai Province in the DRC.

Methods: A cross-sectional survey of 49 Health Facilities (HFs) integrating quantitative and qualitative data collection was conducted in 18 Health Zones in Kasai Province in the DRC. Documentary review, interviews and direct observation of HFs were performed to collect data. Pearson's chi-squared test was performed to establish the relation between variables.

Results: Nearly $54 \%$ of visited HFs population had a geographical access to maternal and child health services and the majority of medical acts were unaffordable. Basic and comprehensive emergency obstetric care $(\mathrm{EmOC})$ were offered respectively by only $11.8 \%$ and $7.6 \%$ of $\mathrm{HF}$ and none provided high quality basic or comprehensive EmOC. This low availability and quality of EmOC are due to the insufficiency of necessary inputs and personal for maternal and child health services in the majority of HFs.

Conclusion: The situation of maternal and child health services is very precarious in Kasai Province. The improvement of EmOC coverage will require rehabilitation of infrastructure, dotation of equipment, regular supply of medicines and strengthening of human resource capacity.

\section{Plain English Summary}

The Democratic Republic of the Congo (DRC) is one of 5 countries in the world, where many women die at delivery and several children die before their fifth birthday. Kasai is one of region of DRC, which is affected by this problem. Despite this overriding concern, almost no studies have been conducted to assess maternal and child situation in this region. Therefore, this study assesses access, availability, and quality of maternal and child health services in this region. Data was collected in 18 hospitals and 31 health centers using review of reports, interviews and direct observation of structures. Our study showed that only half of the population's residences was located at a distance, which allowed them easy access to health facilities and the majority of medical acts was unaffordable. In addition, the care related to maternal and child health was poor and very precarious. The improvement of maternal and child health services of Kasai region will require rehabilitation of infrastructure, dotation of equipment, regular supply of medicines and strengthening of human resource capacity.

\section{Introduction}


Maternal and child mortality are major public health concerns in majority of low-income countries. In 2015 , nearly 88 percent of maternal deaths worldwide occurred in Sub-Saharan Africa $(66,3 \%)$ and in Southern Asia $(21,7 \%)[1,2]$ and approximately 81 percent of under-five deaths in the world occurred in Sub-Saharan Africa $(49,6 \%)$ and in Southern Asia $(31,8 \%)[3,4]$.

The Democratic Republic of the Congo (DRC) is classified among the 5 countries with the highest global maternal mortality ratio (MMR) (846 deaths per 100,000 live births) and the highest under-five mortality rate (U5MR) (104 deaths per 100,000 live births) worldwide [ $2,3,5]$. This country did not achieve the objectives of millennium development goals (MDG) 4 and $5[3,4,6,7]$. Within DRC, 14 provinces have high U5MR and MMR: Tanganyika, Haut-Lomami, Sankuru, Maniema, Lomami, Tshuapa, Kongo Central, Sud-Kivu, Kasai-Central, Lualaba, Mongala, Sud-Ubangi, Kwango, and Kasai [5].

Maternal deaths are mainly caused by obstetric haemorrhage, infections (sepsis), unsafe abortion, hypertension (eclampsia), and prolonged and obstructed labour [ 1, 2]. The leading causes of neonatal mortality (0-27 days of existence) are : preterm birth complications, intrapartum-related complications (birth asphyxia), congenital abnormalities and infection (neonatal sepsis and meningitis, pneumonia, tetanus, and diarrhoea) $[3,4]$. Moreover, the leading causes of under-five mortality are: malaria, pneumonia, diarrhoea, meningitis, AIDS, measles and pertussis [ 3,4$]$.

The first 24 hours after birth are a very critical period for the survival of the woman and the new-born [ 1 , 2]. To reduce maternal and child mortality, packages of reproductive, maternal, new-born, and child health (RMNCH) interventions were developed in the form of the Lives Saved Tool (LiST) [8]. These evidencebased interventions are provided in services of health facilities (HFs) commonly named emergency obstetric care (EmOC) $[9,10]$.

For the effective implementation of these intervention packages, EmOC requires sufficient inputs and qualified personnel [11]. The available and accessible HFs with sustainable infrastructure, qualified and trained staff in RCMNH package, sufficient equipment, materials, essential drugs and delivery follow-up tools will be better equipped to properly manage potentially fatal obstetric complications and prevent maternal death $[12,13]$.

Seven basic signal functions are included in basic EmOC: parenteral administration of anticonvulsants, antibiotics and oxytocin, basic neonatal resuscitation, manual placenta extraction, removal of retained products, and assisted vaginal delivery. Blood transfusion and caesarean section are the other signal functions, which are included in comprehensive EmOC [14].

Coverage of each high-impact RCMNH interventions must be increased from current levels to 90 percent to achieve the targets of the Sustainable Development Goals (SDG) by $2030[1,3]$.

The evaluation of the access, availability and quality of EmOC in the DRC remains poorly documented. The study by Casey et al conducted in hospitals of five provinces of the DRC (Kasai Occidental, Kinshasa, Maniema, Province Orientale, and Sud Kivu) found that none hospital provided a basic EmOC or 
comprehensive EmOC [15]. A research conducted in three western provinces of the DRC according to the old configuration (Bandundu, Bas-Congo, Kinshasa) estimated at $6 \%$ of health structures with the EmOC [16]. Another research carried out in all provinces of the DRC assessed the application of active management during the third stage of labor and the use of partogram [17]. The study by Mpunga Mukendi et al assessed the availability, quality and equity of EmOC at the national level of the DRC [18].

However, almost no studies have addressed the aspect of the population's affordability to these services in the DRC. Furthermore, almost no research was conducted in the central provinces of the DRC after the new administrative division and especially in those concerned with the problem of maternal and child mortality, such as Kasai. In 2017, the U5MR of Kasai province was estimated at 169 children deaths per 1,000 live births, highest ratio in the country. This province also had a higher MMR, 549 maternal deaths per 1,000 live births [5]. The aim of this study was to assess the access, availability and quality of emergency obstetric care in HFs of Kasai Province in the DRC.

\section{Methods}

\section{Study design}

A cross-sectional survey, using mixed methods, was conducted in 2019 and quantitative as well as qualitative data of maternal and child health were collected.

\section{Setting}

The study was carried out in Kasai, one of 26 provinces of the DRC. Located in the south-central part of DRC, Kasai covers an area of $95,631 \mathrm{~km}^{2}$ (Fig. 1) and the population was estimated at 5,193,271 inhabitants in 2018 [19]. The province is inhabited by three main ethnic groups: the Luba-Kasai, the Kuba et the Lunda-Tshokwe. Farming, industrial and artisanal mining are the main economic activities. In health terms, Kasai is subdivided into 18 Health Zones $(\mathrm{HZ})$ and includes 18 General Referral Hospitals (GRH), 395 Health Areas (HA) with 448 Health Centers (HC) and 703 Health Posts (HP). The HZ constitutes the operational level of the health pyramid of DRC. Each $\mathrm{HZ}$ includes one GRH and 1-20 HCs. Each HZ has a population between 100,000 and 300,000 inhabitants [19].

\section{Study population and sampling procedures}

All $18 \mathrm{GRH}$ s of this province were included in the survey. Thirty-one HCs were included in survey according to follow inclusion criteria:

a) Population covered more than 10,000 inhabitants; (b) a high MMR; (c) a high U5MR; and (d) postpartum high-rate of obstetric complications.

A systematic random sample of HCs was performed.

\section{Data collection and study procedures.}


Data were collected from February 23 to March 14, 2019. The survey combined quantitative and qualitative data collection mixed methods. The quantitative approach was first carried out using direct interviews with the RMNCH heads of the selected structures using a questionnaire. This approach allowed to perform documentary review (the annual or monthly reports of each zone and health area). The qualitative approach was performed using first semi-structured individual interviews with the chief medical officers of $\mathrm{HZs}$ and the RMNCH heads of the selected structures. Then, direct observation of health facilities was performed. The study was preceded by a pilot test in the HFs, that was not selected in the survey.

Provincial type Shapefile was downloaded from free and open website (https://data.humdata.org/dataset/drcongo-settlements). Geographical accessibility of the population was measured by computing the distance between the residence of the population and the HF. The latter was considered geographically accessible if the population lived within a radius of $5 \mathrm{~km}$ or lived near a natural obstacle (rivers, mountains, etc.) preventing him from reaching the CS within an hour's walk [20]. Affordability was assessed using standardized and adapted methodology of World Health Organisation (WHO) and Health Action International (HAI) [21]. First, Prices of medicines and medical acts were collected in the Congolese Franc. The average exchange rate used was $1 \$=1675.5$ Congolese Franc [22] Second, affordability was calculated according the number of days needed to pay for standard essential medicines or medical acts on the lowest daily income of the population (nearly $0.85 \$$ by person) [19]. Medicines or medical acts that required more than daily income to pay were considered unaffordable. The qualification and the training of health professionals in $\mathrm{RMNCH}$ package were collected using annual reports of $\mathrm{HZ}$. Then, health professionals were classified into 3 categories: nurses A2 level (secondary level education), nurses' A1 level (undergraduate university level) and licensed nurses (completed university level). Availability was assessed by the physical presence of infrastructures, equipment / healthcare materials, essential medicines and consumables in sufficient stock and delivery and data reporting tools at the time of the survey. The equipment / healthcare materials, essential medicines and consumables, which were collected during the survey, were adapted from list of interventions proposed by experts of RMNCH $[1,23]$. An infrastructure was considered sustainable if it had the minimum $11 \mathrm{RMNCH}$ services (delivery room with delivery bed with new-born corner water drainage and soakaway, incinerator, light source, labor room, space for prenatal, postnatal and preschool consultations, safe water source or hand washing device, examining table, postpartum ward, space for sterilization / presence of the autoclave or puppinel, room for emergency Caesarean section, blood transfusion station) [1]. The unit price and the number of stockouts of each drug during the last 6 months have been estimated.

The basic EmOC was available if the HFs provides all seven defined signal functions of a basic EmOC at the time of the survey or the 3-month period prior to the survey. The comprehensive EmOC was available if the HF provides all nine defined signal functions of a comprehensive EmOC at the time of the survey or the 3-month period prior to the survey.

The quality of basic EmOC and comprehensive EmOC was based on criteria used in recent researches carried out in the DRC [18]. Four criteria were used for determining the quality of basic EmOC: availability 
of essential medicines and consumables; availability of material and equipment; the presence of at least one health professional trained in EmOC in the 2 years prior to the survey, and availability of delivery and data reporting tools. Five criteria were used for determining the quality of comprehensive EmOC: diagnostic capacity to perform blood grouping and cross-tabulation tests, availability of essential medicines and consumables; availability of material and equipment; the presence of at least one health professional trained in comprehensive EmOC or anaesthesia or surgery in the 2 years prior to the survey, and availability of delivery and data reporting tools.

\section{Data analyses}

Collected data were recorded on Microsoft Exce ${ }^{\circledR} 2016$ files. All statistical analyses were performed in $\mathrm{R}^{\circledR}$ 4.0.0. The map of Kasai Provincial Health Division was drawn using the free software QGIS 3.4. As the study consisted mainly of discrete quantitative variables, they were presented as proportions (\%). Pearson's chi-squared test was performed to establish the relation of availability and quality of EmOC with different types of HF. We used an alpha significance level of 0.05 to test all hypotheses.

\section{Results}

Among the HFs (GRHs and HCs) surveyed, 32 were public (65.2\%), 15 were private (30.1\%) and two belonged to mission sector. A total of 247 health workers were interviewed.

\section{Access to healthcare}

\section{Geographical accessibility of the population to health facilities}

The geographical accessibility was insufficient. Approximately half of the population lives at distances greater than $5 \mathrm{~km}$ or near a natural obstacle (rivers, mountains, etc.) preventing him from reaching the CS within an hour's walk (Fig. 2), which do not make it easier for population to access to HFs.

\section{Affordability of medicines and medical acts}


Table 1

Prices and affordability of medicines and medical acts in HFs of Kasai Health Division, 2019

\begin{tabular}{|c|c|c|c|}
\hline $\mathbf{N}^{\circ}$ & Medicines/medical acts & $\begin{array}{l}\text { Unit Price (in } \\
\text { USD) }\end{array}$ & $\begin{array}{l}\text { Affordability per treatment unit (in } \\
\text { days) }{ }^{a}\end{array}$ \\
\hline 1 & Oxytocin Injection $10 \mathrm{IU}, 1 \mathrm{ml}$ & 0.09 & 0.1 \\
\hline 2 & Misoprostol $200 \mu \mathrm{g}$ Tablet & 0.13 & 0.2 \\
\hline 3 & $\begin{array}{l}\text { Magnesium sulfate Injection } \\
500 \mathrm{mg} / \mathrm{ml}\end{array}$ & 0.29 & 0.3 \\
\hline 4 & Admission costs in $\mathrm{HCs}$ & 0.6 & 0.7 \\
\hline 5 & Admission costs in GRHs & 1 & 1.2 \\
\hline 6 & Blood transfusion & 6.04 & 7.1 \\
\hline 7 & Eutocic childbirth & 4.72 & 5.6 \\
\hline 8 & Distocic childbirth & 15.10 & 17.8 \\
\hline 9 & Caesarean section & 36.12 & 42.5 \\
\hline \multicolumn{4}{|c|}{ GRH General Referral Hospital, HC Hospital Center. } \\
\hline \multicolumn{4}{|c|}{$\begin{array}{l}\text { a Affordability per treatment unit was calculated according to the number of days needed to pay for } \\
\text { standard essential medicines or medical acts on the lowest daily income of the population (nearly } \\
0.85 \$ \text { by person). Medicines or medical acts that required more than daily income to pay were } \\
\text { considered unaffordable. }\end{array}$} \\
\hline
\end{tabular}

With the exception of the admission costs and essential drugs, the prices of medical acts were unaffordable for the population (Table 1).

\section{Availability and sustainability of infrastructure with RMNCH services}

\section{Availability of infrastructure with RMNCH services}


Table 2

Availability of infrastructure with RMNCH services in HFs of Kasai Health Division, 2019

\begin{tabular}{|llll|}
\hline $\mathbf{N}^{\mathbf{0}}$ & RMNCH services & Number $^{1}$ & $\%$ \\
\hline 1 & $\begin{array}{l}\text { Delivery room with delivery bed with new-born corner, water drainage and } \\
\text { soakaway }\end{array}$ & 15 & 29.7 \\
\hline 2 & Incinerator & 14 & 28.1 \\
\hline 3 & Light source & 15 & 30.4 \\
\hline 4 & Labor room & 14 & 29.2 \\
\hline 5 & Space for prenatal, postnatal and preschool consultations & 16 & 31.8 \\
\hline 6 & Safe water source or hand washing device & 14 & 29.5 \\
\hline 7 & Examining table & 14 & 27.8 \\
\hline 8 & Postpartum ward & 14 & 28.9 \\
\hline 9 & Space for sterilization / presence of the autoclave or puppinel & 13 & 27.1 \\
\hline 10 & Room for emergency Caesarean section & 10 & 20.2 \\
\hline 11 & Blood transfusion station & 10 & 19.8 \\
\hline 1 A total of 49 HFs surveyed including 18 GRHs and 31 HCs. & & \\
\hline
\end{tabular}

Infrastructures with RMNCH services were available in only one third of surveyed HF. The least available RMNCH service was space for sterilization or presence of the autoclave or puppinel (27.1\%), followed by room for emergency Caesarean section (20.2\%) and blood transfusion station (19.8\%) (Table 2). The availability of infrastructures was significantly higher in private HF than in public HF $(p<0.001)$.

\section{Equipment / healthcare and travel materials of RMNCH services}


Table 3

Equipment / healthcare and travel materials of RMNCH services in HFs of Kasai Health Division, 2019

\begin{tabular}{|llll|}
\hline $\mathbf{N}^{\mathbf{0}}$ & Equipment / healthcare and travel materials & Number $^{1}$ & $\%$ \\
\hline 1 & Flexible gynaecological examination light & 5 & 10.5 \\
\hline 2 & Warm table or table with heat source & 5 & 9.9 \\
\hline 3 & Baby scale & 15 & 31.4 \\
\hline 4 & Negative pressure vacuum with a suction probe & 5 & 9.7 \\
\hline 5 & Sterilizer or pressure cooker & 17 & 35.5 \\
\hline 6 & Blood pressure monitor and stethoscope & 15 & 31.6 \\
\hline 7 & Obstetric stethoscope (fetoscope) & 18 & 37.1 \\
\hline 8 & Single-use detachable pear & 17 & 35.7 \\
\hline 9 & Self-inflatable ventilation bag 250-500 ml and face mask No and N $^{\circ} 1$ & 6 & 11.3 \\
\hline 10 & Delivery box & 15 & 30.2 \\
\hline 11 & Box for examination / suture of the vagina and cervix & 15 & 29.8 \\
\hline 12 & Box of vaginal specula of different sizes (small, medium and large) & 12 & 25.1 \\
\hline 13 & Suction cup and / or forceps & 7 & 15.0 \\
\hline 14 & Ambulance & 1 & 0.02 \\
\hline 1 A total of 49 HFs surveyed including 18 GRHs and 31 HCs. & & \\
\hline
\end{tabular}

\section{Sustainability of infrastructure with RMNCH services}

Approximately $80 \%$ of infrastructures of visited HFs were unsustainable (Fig. 3). They were more sustainable infrastructures in private HFs than in public HFs $(p<0.0001)$.

\section{Qualification and the training of health professionals in RMNCH package}

Nearly half of health providers was low skilled (nurses' level A2) (Fig. 4). Among them, $18 \%$ were trained in RMNCH package. Only $14 \%$ of skilled personal (nurses' level A1) were also midwives. Comparison of qualification and training of health professionals in $\mathrm{RMNCH}$ package between private and public HFs showed no significant difference $(p>0.05)$.

\section{Availability of essential medicines in sufficient stock of RMNCH services}


Table 4

Availability of essential medicines in sufficient stock of RMNCH services in HFs of Kasai Health Division, 2019

\begin{tabular}{|llll|}
\hline $\mathbf{N}^{\mathbf{0}}$ & Availability of essential medicines in sufficient stock & Number $^{1}$ & $\%$ \\
\hline 1 & Silver nitrate (1\%) or Argyrol (0.5\%) & 8 & 16.6 \\
\hline 2 & Vitamin K1 ampoule 1 mg / ml & 9 & 17.8 \\
\hline 3 & Papaverine, N-butylscopolamine & 12 & 20.2 \\
\hline 4 & Chlorine-based disinfectants & 20 & 49.5 \\
\hline 5 & Disinfectants for cleaning hands & 20 & 41.3 \\
\hline 6 & Combinations of Artesunate, Quinine & 20 & 41.7 \\
\hline 7 & Antiseptic solutions & 21 & 43.2 \\
\hline 8 & Diazepam, Magnesium sulfate, Calcium gluconate & 33 & 67.4 \\
\hline 9 & Ampicillin, Gentamicin & 32 & 64.9 \\
\hline 10 & Physiological saline 0.9\%, Ringer lactate, glucose solution 50\% & 33 & 67.5 \\
\hline 11 & Paracetamol & 33 & 67.1 \\
\hline 12 & Vitamin A, Folic acid & 33 & 68.2 \\
\hline 13 & Oxytocin / Misoprostol & & \\
\hline 1 A total of 49 HFs surveyed including 18 GRHs and 31 HCs. & & \\
\hline
\end{tabular}

Between 70 to $90 \%$ of surveyed HFs did not have minimum equipment / healthcare materials of RMNCH services (Table 3).

The least equipment was negative pressure vacuum with a suction probe $(9.7 \%)$, warm table or table with heat source (9.9\%), flexible gynaecological examination light (10.5\%), and suction cup and / or forceps (15\%). Only one GRH had an ambulance to transport patients in an emergency (Table 3). The availability of equipment was significantly higher in private HFs than in public HF $(p<0.0001)$.

The least essential medicines were Silver nitrate (1\%) or Argyrol (0.5\%) (16.6\%), vitamin K1 ampoule $1 \mathrm{mg}$ / $\mathrm{ml}$ (17.8\%), Papaverine, N-butylscopolamine (20.2\%), and Chlorine-based disinfectants (19.5\%).

Parenteral anticonvulsants (Diazepam, Magnesium sulfate, Calcium gluconate) were available in only $43.2 \%$ of HFs. Almost $70 \%$ of HF had uterotonic drugs (Oxytocin, Misoprostol) and parenteral antibiotics (Ampicillin, Gentamicin) (Table 4).

\section{Availability, the content and the completion of delivery and data reporting tools of RMNCH services}


The delivery and data reporting tools were available in almost all the surveyed facilities (approximately $95 \%)$. This information was updated and well-maintained. Staff periodically reviewed patient records (Table 5).

\section{Availability and quality of EmOC}

Parenteral administration of oxytocin was the most performed signal function (63.6\%), followed by Manual placenta extraction (57.8\%) and parenteral administration of antibiotics (53.9\%). The least performed signal functions were assisted vaginal delivery (20.9\%), parenteral administration of sedatives (49.8\%), basic neonatal resuscitation (50.6\%), and removal of retained products (50.8\%) (Fig. 5).

Among surveyed HFs, $11.8 \%$ provided basic EmOC and 7.6\% offered comprehensive EmOC (Fig. 5). Basic and comprehensive EmOC were better provided in private HFs than in public HF $(p<0.001)$. According to criteria of quality, none of surveyed HF provided high quality basic or comprehensive EmOC.

Table 5

Availability, the content and the completion of delivery and data reporting tools of RMNCH services in HF of Kasai Health Division, 2019

\begin{tabular}{|llll|}
\hline $\mathbf{N}^{\circ}$ & $\begin{array}{l}\text { Availability, the content and the completion of delivery and data reporting } \\
\text { tools }\end{array}$ & Number & \% \\
\hline 1 & Are the tools (partographs, sheets and registers) available? & 46 & 94.7 \\
\hline 2 & Are they updated and well-maintained? & 36 & 74.3 \\
\hline 3 & Are all the columns filled? & 36 & 73.5 \\
\hline 4 & Is there a column for reporting the diagnoses? & 36 & 73.8 \\
\hline 5 & Are diagnoses reported regularly in this column? & 39 & 79.4 \\
\hline 6 & Is there a column for reporting the treatment? & 40 & 81.5 \\
\hline 7 & Is there a column for reporting obstetrical and neonatal complications? & 38 & 77.9 \\
\hline 8 & Are patient records periodically reviewed by staff? & 36 & 77.7 \\
\hline 1 A total of 49 HFs surveyed including 18 GRHs and 31 HCs. & & \\
\hline
\end{tabular}

\section{Discussion}

The population (nearly $50 \%$ ) had limited or poor geographic access to RMNCH services and the majority of medical acts were unaffordable because of high prices.

Basic EmOC was offered in only $11.8 \%$ of HFs, comprehensive EmOC was offered in only $7.6 \%$ of $\mathrm{HF}$, and none of surveyed HFs provided high quality basic or comprehensive EmOC. 
The reasons of this low availability and quality of EmOC are the insufficiency of necessary inputs and personal for the offering RMNCH services in the majority of HFs. Only one third of surveyed HFs had available infrastructures with RMNCH services, including nearly $80 \%$ were unsustainable. Almost half of health providers was low skilled and the majority was not trained in $\mathrm{RMNCH}$ package. Only 10 to $30 \%$ of surveyed HFs had minimum equipment / healthcare materials of RMNCH services. Only one facility had an ambulance to transport patients in an emergency. Between 40 to $80 \%$ surveyed facilities did not have a category of essential medicines, consumables and small medical equipment in the last 6 months. The delivery and data reporting tools were available, updated and well-maintained in almost all the surveyed facilities.

To our knowledge, this survey is the first of its kind, that was conducted in Kasai province over twenty years. Another strength of this study is that it was conducted in all $18 \mathrm{GRHs}$ of this province, allowing to have crucial information on the RMNCH in these facilities. An additional strength of this survey is the use of a standardized WHO and HAI methodology, allowing us to assess affordability [21]. The other items collected during the survey, were adapted from list of interventions proposed by experts of RMNCH $[1,23]$.

Nevertheless, our study presented several limitations that where clearly identified and partially resolved for some of it. The study was conducted in just $31 \mathrm{HCs}$, representing only $20 \%$ of these facilities in Kasai province. However, the sampling (stratified random sampling) used allowed to ensure the representativeness of the HCs in all axes of each HZs. As part of the continuity of care, this survey should also be conducted at the family/community level. The survey study did not conduct at this level, because we assumed that very little activity was carried out at this level.

The poor geographic access to RMNCH services and the unaffordability of essential drugs and medical acts were also found in other studies. A research showed that access to RMNCH services was impeded by affordability and the distance of the patient's residence from the health facility (longest travel times) [24]. Other studies highlighted that long distances associated with poor transportation conditions, can be potential key barriers to utilization of RMNCH services [25, 26]. The limited access to RMNCH services can lead to late identification and referral for high-risk pregnancies [13].

Our study showed low availability of EmOC in HFs of Kasai province. Basic and comprehensive EmOC were offered respectively by only $11.8 \%$ and $7.6 \%$ of HFs and none provided high quality basic or comprehensive EmOC. These results are largely in line with those found in other researches in the DRC $[15,16,18,27]$. This work revealed that nearly 40 to $50 \%$ of HFs did not provide any signal functions of basic EmOC. Administration of sedatives, basic neonatal resuscitation, removal of retained products, and assisted vaginal delivery were the least performed signal functions. The not performing of these signal functions was also found in other studies $[14,18]$. The lack of these signal functions may be explained by the poor management in HF of preeclampsia/ eclampsia, prevention of postpartum haemorrhages, and neonatal asphyxia, which are main causes of maternal and neonatal mortality $[11,14,18]$.

The most common reasons of not performing of basic EmOC signal functions may be unavailability and unsustainability of infrastructures, low skilled and not trained personal in RMNCH package, insufficient of 
equipment and healthcare materials, lack of essential medicines, and unavailability of delivery and data reporting tools $[14,18]$. Almost of these reasons were found in our study.

A study conducted in rural India showed that improved available and sustainable infrastructures of public health facilities could lead to increased utilization of health services [26]. Another research highlighted that basic sustainable infrastructures can play an important role in improving access to RMNCH services [28].

Some researches indicated that skilled and trained health providers could recognise and manage rapidly high-risk pregnancy and therefore could prevent delivery complications, maternal and new-born morbidity and mortality $[13,26,29]$.

The study by Patel et al. also observed that availability of equipment / healthcare materials of sufficient quality strongly encourages women to give birth in public health facilities [26]. This is similar to studies elsewhere; Cole-Ceesay et al. showed that supplying adequate new equipment and materials could help to improve the management of emergencies during pregnancy, childbirth, infancy and childhood [29].

Essential medicines, consumables and small medical equipment were not available in nearly 40 to $80 \%$ surveyed facilities during a period of 6 months. This result is in accordance with those found by other studies $[13,26,29]$. The availability of essential emergency medicines such oxytocin, misoprostol, magnesium sulphate, antibiotics, and fluids could prevent post-partum haemorrhage, eclampsia and sepsis, which are the common causes of deaths among women and children in low-income countries [29].

The delivery and data reporting tools were available, updated and well-maintained in almost all the surveyed facilities. This result was contrary to other study, where data reporting was neither complete nor accurate [30]. The difference may be explained by the fact that the majority of facilities of Kasai province regularly received the data collection tool from a financial partner, which also supervised their filling.

\section{Conclusion}

Our study showed that only half of the population of visited HF can geographically access to RMNCH services and the majority of medical acts was unaffordable. In addition, the availability and quality of EmOC was low, because mainly provided in low available and unsustainable infrastructures by low skilled personal, characterised by frequent stock-outs of essential emergency medicines and blatant lack of equipment / healthcare materials. The improvement of EmOC coverage will require rehabilitation of infrastructure, dotation of equipment, regular supply of medicines and strengthening of human resource capacity.

\section{Abbreviations}


AIDS: Acquired Immune Deficiency Syndrome; DRC: Democratic Republic of the Congo; EmOC:

Emergency Obstetric Care; GRH: General Reference Hospitals; HA: Health Area, HAl: Health Action International; HC: Health Centers; HF: Health Facility ; HP: Health Post; HZ: Health Zone; LiST: Lives Saved Tool; MMR: Maternal Mortality Ratio; MDG: Millennium Development Goals; QGIS: Quantum Geographic Information System; RMNCH: Reproductive, Maternal, New-Born, And Child Health; SANRU: Santé Rurale; SDG: Sustainable Development Goals; U5MR: Under-Five Mortality Rate; UN: United Nations; WHO: World Health Organisation.

\section{Declarations}

\section{Acknowledgments}

We thank all persons, who assisted the drafting of this article. The authors thank also Professor Ntabe Namegabe for coordinating the data collection for this research. We also acknowledge the field workers.

\section{Funding}

The project was funded by the Swedish Government, through its International Development Cooperation Agency, "SIDA". The founder had no role in study design, data collection and analysis, in the writing of paper, and decision to publish it.

\section{Availability of data and materials}

The datasets supporting the conclusions of this article are included within the article and its additional files.

\section{Authors' contributions}

$\mathrm{BN}, \mathrm{AN}, \mathrm{PN}$ and BM contributed to the conception and design of the study. NN, JJM and HB acquired the data. BN, FM, NMK and AK analyzed and interpreted the data. BN, AN, PN and BM drafted the manuscript and all authors revised it for important intellectual content. All authors reviewed and edited multiple drafts and approved the final manuscript for publication.

\section{Ethics approval and consent to participate}

This research was approved by DRC Protestant University ethics committee (ref: CEUPC 0059).

\section{Consent for publication}

Not applicable.

\section{Competing interests}

The authors declare that they have no competing interests. 


\section{References}

1. Black R, Laxminarayan R, Temmerman $M$, Walker N, éditeurs. Disease Control Priorities, Third Edition (Volume 2): Reproductive, Maternal, Newborn, and Child Health [Internet]. The World Bank; 2016 [cité 19 juin 2020]. Disponible sur: http://elibrary.worldbank.org/doi/book/10.1596/978-1-4648-0348-2

2. WHO. Trends in maternal mortality: 1990-2015: estimates from WHO, UNICEF, UNFPA, World Bank Group and the United Nations Population Division. World Health Organization; 2015.

3. Liu L, Oza S, Hogan D, Chu Y, Perin J, Zhu J, et al. Global, regional, and national causes of under-5 mortality in 2000-15: an updated systematic analysis with implications for the Sustainable Development Goals. The Lancet. 2016;388(10063):3027-3035.

4. You D, Hug L, Ejdemyr S, Idele P, Hogan D, Mathers C, et al. Global, regional, and national levels and trends in under-5 mortality between 1990 and 2015, with scenario-based projections to 2030: a systematic analysis by the UN Inter-agency Group for Child Mortality Estimation. The Lancet. 2015;386(10010):2275-2286.

5. INS. Enquête par grappes à indicateurs multiples, 2017-2018, rapport de résultats de l'enquête. Kinshasa, République Démocratique du Congo. 2019.

6. You D, Hug L, Ejdemyr S, Beise J. Levels and trends in child mortality: Report 2015. Estimates Developed by the UN Inter-Agency Group for Child Mortality Estimation. U N Child Fund N Y. 2015;

7. Liu L, Oza S, Hogan D, Perin J, Rudan I, Lawn JE, et al. Global, regional, and national causes of child mortality in 2000-13, with projections to inform post-2015 priorities: an updated systematic analysis. The Lancet. 2015;385(9966):430-440.

8. Jones G, Steketee RW, Black RE, Bhutta ZA, Morris SS, Group BCSS. How many child deaths can we prevent this year? The lancet. 2003;362(9377):65-71.

9. Lee AC, Cousens S, Wall SN, Niermeyer S, Darmstadt GL, Carlo WA, et al. Neonatal resuscitation and immediate newborn assessment and stimulation for the prevention of neonatal deaths: a systematic review, meta-analysis and Delphi estimation of mortality effect. BMC Public Health. 2011;11(S3):S12.

10. WHO. Standards for improving quality of maternal and newborn care in health facilities. 2016;

11. Mirkuzie AH, Sisay MM, Reta AT, Bedane MM. Current evidence on basic emergency obstetric and newborn care services in Addis Ababa, Ethiopia; a cross sectional study. BMC Pregnancy Childbirth. 2014;14(1):1-8.

12. Friberg IK, Kinney MV, Lawn JE, Kerber KJ, Odubanjo MO, Bergh A-M, et al. Sub-Saharan Africa's mothers, newborns, and children: how many lives could be saved with targeted health interventions? PLoS Med. 2010;7(6).

13. Bhutta ZA, Cabral S, Chan C, Keenan WJ. Reducing maternal, newborn, and infant mortality globally: An integrated action agenda. Int J Gynecol Obstet. 2012;119(S1):S13-7.

14. Teshoma KR, Eticha CT. Availability and quality of emergency obstetric and newborn care service in Dire Dawa, Ethiopia. J Women's Health Care. 2016;5(5). 
15. Casey SE, Mitchell KT, Amisi IM, Haliza MM, Aveledi B, Kalenga P, et al. Use of facility assessment data to improve reproductive health service delivery in the Democratic Republic of the Congo. Confl Health. 2009;3(1):12.

16. Ministère de la Santé Publique, Fonds des Nations Unies pour la, population, Organisation Mondiale de la Santé, Averting Maternal Death, and Disability. Soins obstétricaux et néonatals d'urgence dans les structures de soins en RDC: évaluation des besoins dans trois provinces. Rapport d'enquête:= [Internet]. RDC; 2012. Disponible sur: http://drc.unfpa.org/sites/ default/files/pubpdf/SONU_RAPPORT_ENQUETE_FINAL_DU_7_12_2012. pdf.

17. Ministère de la Santé Publique. Cartographie des interventions et intervenants de la santé de la mère, du nouveau-né et de l'enfant y compris la planification familiale en RD Congo [Internet]. RDC; 2012 [cité 16 déc 2020]. Disponible sur: http://familyplanning-drc.net/docs/Rapport\%20final\%2 0cartographie\%20de\%20la\%20SMNE\%2029\%20octobre\%202012.pdf.

18. Mpunga Mukendi D, Chenge F, Mapatano MA, Criel B, Wembodinga G. Distribution and quality of emergency obstetric care service delivery in the Democratic Republic of the Congo: it is time to improve regulatory mechanisms. Reprod Health. déc 2019;16(1):102.

19. DPS Kasaï. Plan d'action opérationnel 2019, Ministère de la Santé Publique, République Démocratique du Congo. 2019.

20. Maina J, Ouma PO, Macharia PM, Alegana VA, Mitto B, Fall IS, et al. A spatial database of health facilities managed by the public health sector in sub Saharan Africa. Sci Data. 2019;6(1):1-8.

21. WHO. Measuring medicine prices, availability, affordability and price components. World Health Organization; 2008.

22. Central Bank of Congo. Exchange Rates. 2019. http://www.bcc.cd/index.php? option=com_content\&view=article\&id=2831:mardi-10012017\&catid=40:cours-dechange\&ltemid=103. 2019.

23. WHO. Interagency list of medical devices for essential interventions for reproductive, maternal, newborn and child health. 2016;

24. Silal SP, Penn-Kekana L, Harris B, Birch S, Mclntyre D. Exploring inequalities in access to and use of maternal health services in South Africa. BMC Health Serv Res. 2012;12(1):120.

25. Yao J, Murray AT, Agadjanian V. A geographical perspective on access to sexual and reproductive health care for women in rural Africa. Soc Sci Med. 2013;96:60-68.

26. Patel R, Ladusingh L. Do physical proximity and availability of adequate infrastructure at public health facility increase institutional delivery? A three level hierarchical model approach. PLoS One. 2015;10(12):e0144352.

27. Casey SE, Chynoweth SK, Cornier N, Gallagher MC, Wheeler EE. Progress and gaps in reproductive health services in three humanitarian settings: mixed-methods case studies. Confl Health. 2015;9(S1):S3.

28. Fay M, Leipziger D, Wodon Q, Yepes T. Achieving child-health-related Millennium Development Goals: The role of infrastructure. World Dev. 2005;33(8):1267-1284. 
29. Cole-Ceesay R, Cherian M, Sonko A, Shivute N, Cham M, Davis M, et al. Strengthening the emergency healthcare system for mothers and children in The Gambia. Reprod Health. 2010;7(1):21.

30. Mate KS, Bennett B, Mphatswe W, Barker P, Rollins N. Challenges for routine health system data management in a large public programme to prevent mother-to-child HIV transmission in South Africa. PloS One. 2009;4(5):e5483.

\section{Figures}

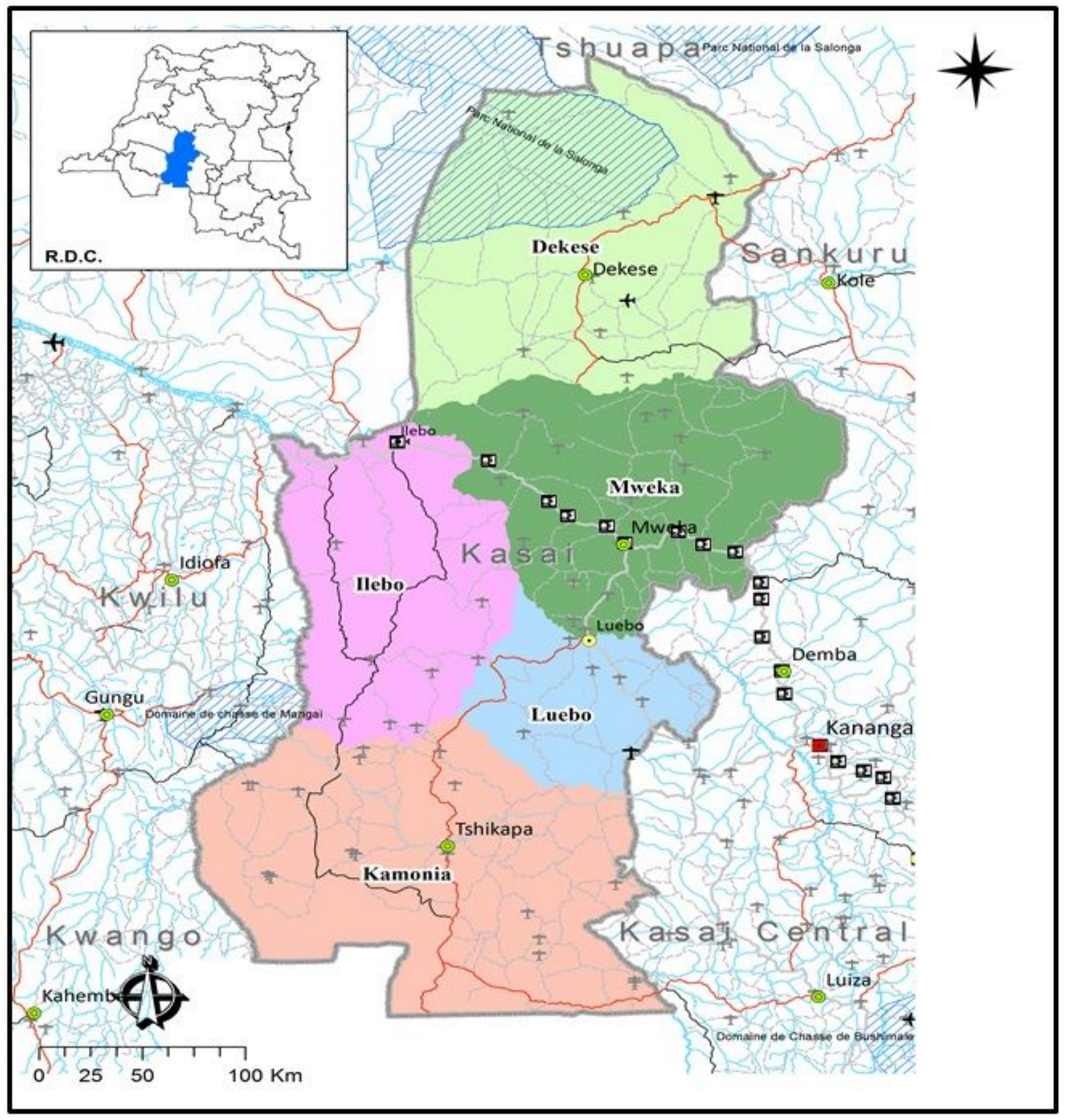

Figure 1 
Map of Kasai Health Division, DRC (Source: The provincial Shapefile downloaded from free and open website (https://data.humdata.org/dataset/drcongo-settlements) was used to elaborate this map with the free software QGIS 12.8. Note: The designations employed and the presentation of the material on this map do not imply the expression of any opinion whatsoever on the part of Research Square concerning the legal status of any country, territory, city or area or of its authorities, or concerning the delimitation of its frontiers or boundaries. This map has been provided by the authors.

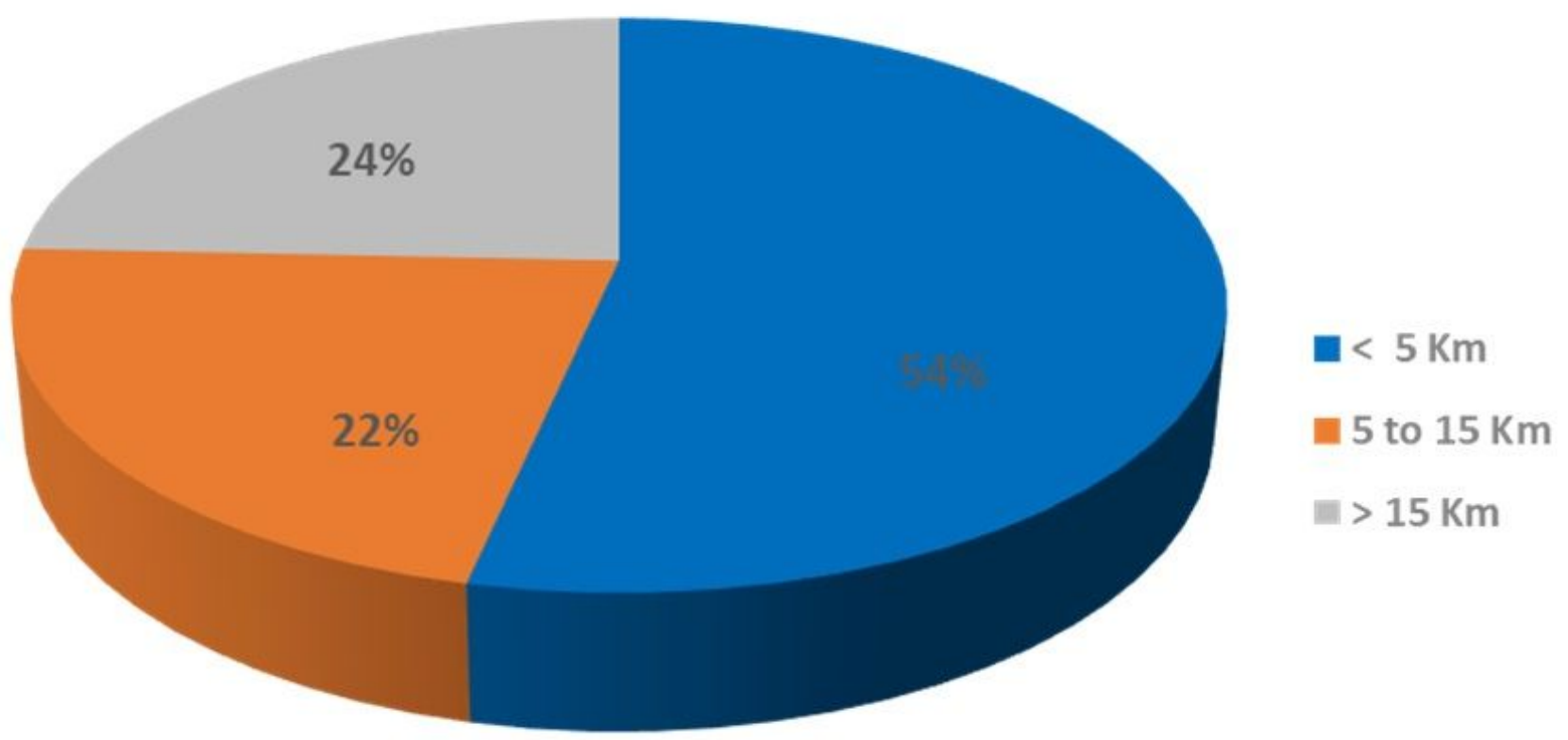

Figure 2

Level of geographical accessibility of the population to HFs of Kasai Health Division, DRC 


\section{$100 \%$ \\ $90 \%$ \\ $80 \%$ \\ $70 \%$ \\ $60 \%$ \\ $50 \%$ \\ $40 \%$ \\ $30 \%$ \\ $20 \%$ \\ $10 \%$ \\ $0 \%$}

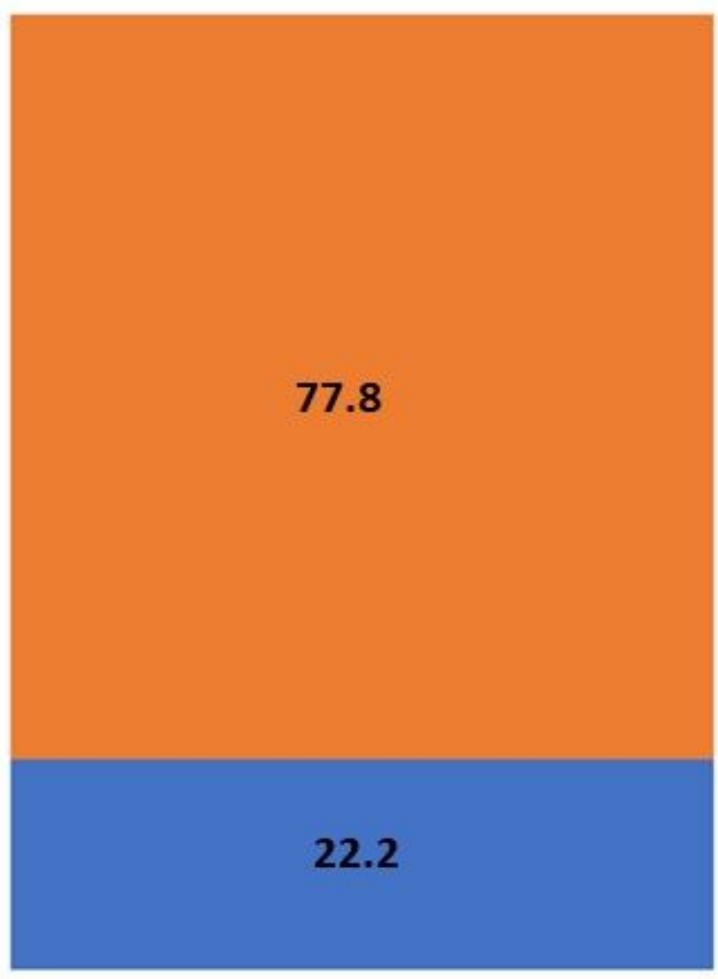

Sustainable structures

- Unsustainable structures

\section{Figure 3}

Sustainability of infrastructure with RMNCH services in HFs of Kasai Health Division, 2019 


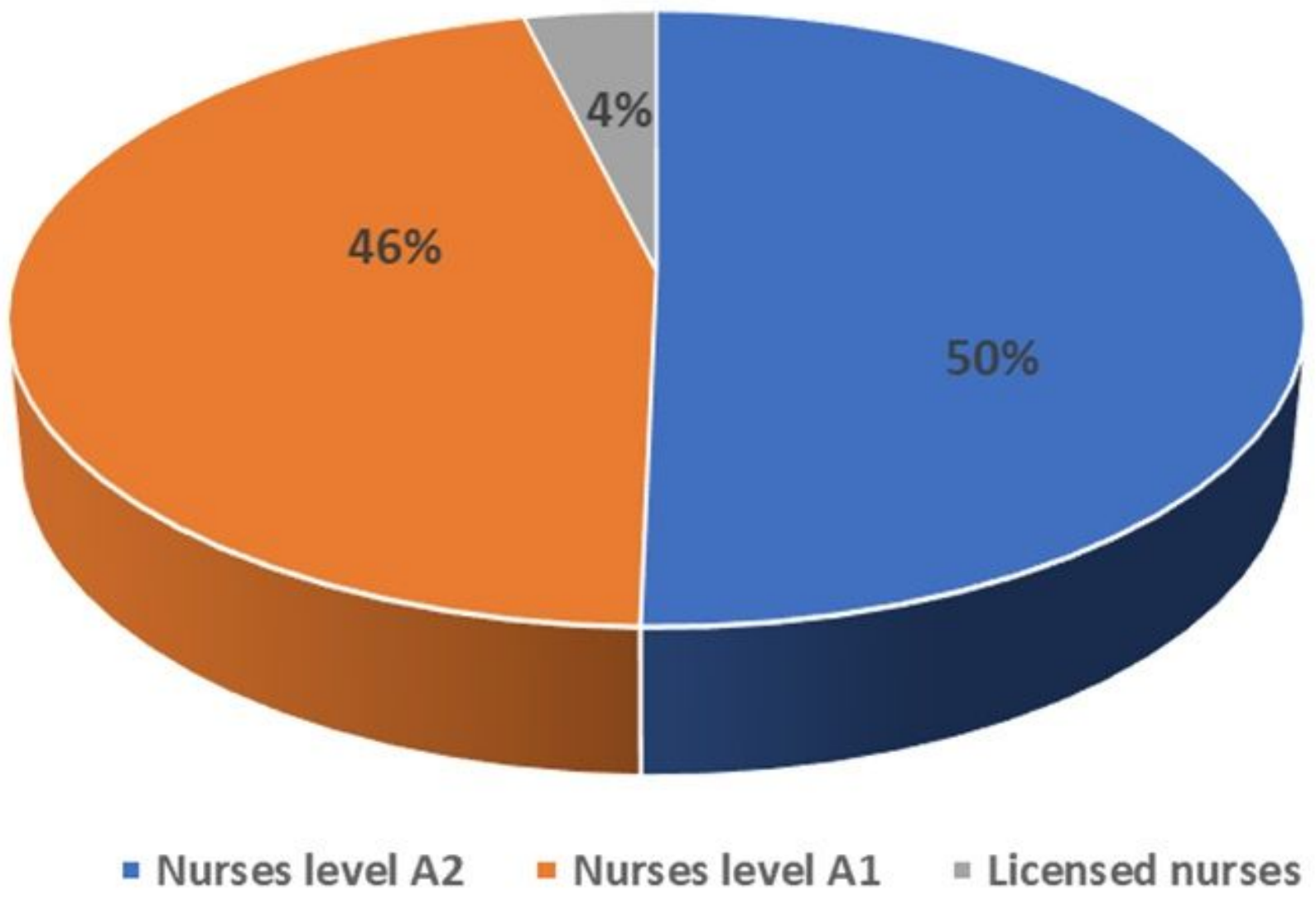

Figure 4

Qualification of health professionals in HFs of Kasai Health Division, 2019 


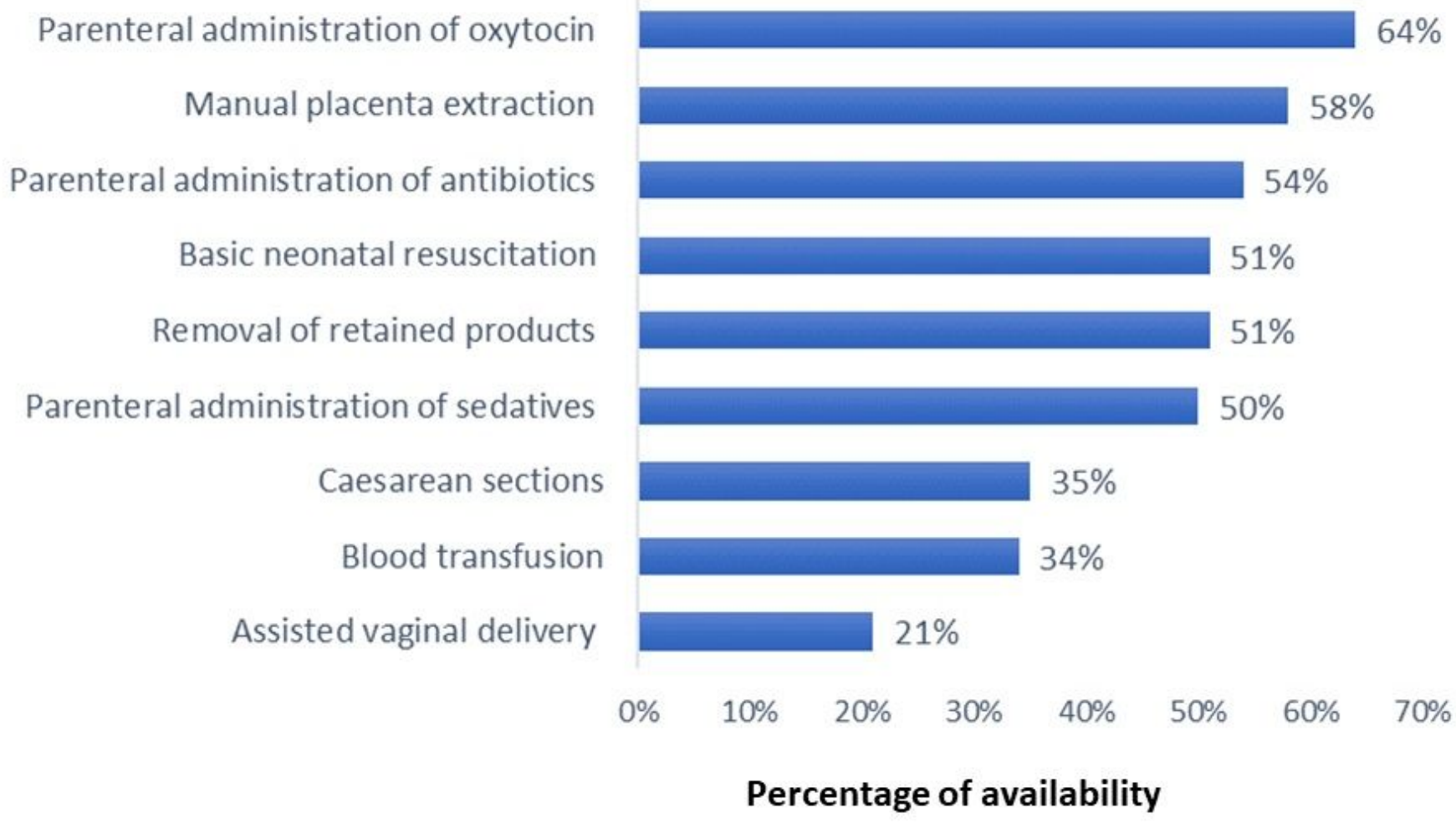

Figure 5

Percentage of HFs performing signal functions of basic and comprehensive EmOC, Kasai Health Division, 2019

\section{Supplementary Files}

This is a list of supplementary files associated with this preprint. Click to download.

- Additionalfile1.xlsx 